\title{
Age, Gender, Level, and Grade Effect on Foreign Language Learning Strategy
}

\author{
Saefurrohman \\ saefurrohman@ump.ac.id \\ Department of English Education, Faculty of Teacher Training and \\ Education, Universitas Muhammadiyah Purwokerto
}

\begin{abstract}
This study aims to explore the relationship of age, gender, level and grade differences on students language learning strategy among Indonesian children who learn English as a foreign language. The participants were 350 students from junior high school in Banyumas, Indonesia The data collection tools were a background questionnaire consisting the variables mentioned and he Strategy Inventory for Language Learning, or SILL After computing the reliability coefficient of the scale and total variance, Pearson correclation were used to see the relationships between language learning strategy and subject variables age, gender, level and grade. The result indicates that there is a relationship between gender and grade in English and language learning strategy in English. However, there is a no relationship between age, level and language learning strategy in English.
\end{abstract}

Keywords: Age, Gender, Level, Grade, and Foreign Language Learning Strategy

\section{Introduction}

Good language learners are commonly considered to be those who can find their own way by taking care of their learning, organizing their language knowledge, and creating their own opportunities for language practice [1]. In addition, to support them in learning a language, they use their experience and strategy [2]. In addition, research involving language learners has also shown that the most active learners appear to use learning strategies that are relevant to the mission, content, self-objective, criteria, motivation and learning level [3][4][5]. It seemed that successful language learners had the potential to excel, while others lacked those skills.

For language learning, learning strategies are important because they are instruments for active, self-directed interaction [6]. Learning strategies should encourage the autonomy of learners in language learning and help learners promote their own accomplishments in language skills. Therefore, learning strategies assist learners to become successful in learning and using a language[7][8].

Learning strategies are the particular thoughts or actions that people use to help them understand, learn or maintain new data[9]. Oxford extends the concept of learning strategies and describes them as "the learner's specific actions to make learning simpler, faster, more enjoyable, more self-directed, more efficient, and more transferable to new situations" [10]

Concerning the effect of age, gender, level and grade on foreign language learning strategy, research suggests that age, gender, level and grade is a considerable predictor that relates to foreign language learning strategy [6][11]. However, some research also stated that age, gender, 
level and grade is also a neglected variable regarding foreign language learning strategy while it is evident that adult and young learners cannot be treated equally in regards to their responses to foreign language learning strategy [12]. This study will therefore examine the correlation of age, gender, level and grade toward the students foreign language learning strategy.

\section{Method}

The goal of this study is to explore some factors influencing the students learning strategy in EFL class. In order to achieve the objective of the research, the quantitative data was adopted to collect descriptive and correlation data in order to explain the features of several groups of students. The students at Senior High School in Purwokerto City were the target respondents for this research. Therefore, the participants of this study were taken only from 9 Senior High schools of Purwokerto city, Indonesia with total 380 students. Oxford Strategy Inventory for Language Learning (SILL) was adopted to know the students language learning strategy [10]. Pearson Product moment correlation using SPSS statistic analysis was used to analyze the data.

\section{Result and Discussion}

\subsection{Characteristic of Respondents (Age, Gender, Level and Grade)}

The data are presented in tabular form for the following demographic characteristics: gender, age, level and grade in English. The result is as follow.

Table 1. Characteristics of Respondents

\begin{tabular}{lcc}
\hline Characteristics & Frequency (n) & Percentage (\%) \\
\hline Gender & 135 & \\
Male & 245 & $35.5 \%$ \\
Female & & $64.5 \%$ \\
Age & 31 & \\
$13-14$ & 264 & $8.2 \%$ \\
$15-16$ & 85 & $69.5 \%$ \\
$17-19$ & & $22.4 \%$ \\
Level & 157 & \\
10 & 122 & $41.3 \%$ \\
11 & 101 & $32.1 \%$ \\
12 & & $26.6 \%$ \\
Grade in English & 16 & \\
$60-69$ & 80 & $4.2 \%$ \\
$70-79$ & 175 & $21.1 \%$ \\
$80-89$ & 109 & $46.1 \%$ \\
$90-100$ & & $28.7 \%$ \\
\hline
\end{tabular}

As shown in Table 1, the majority of respondents are female, consisting of $245(64.5 \%)$ and only 135 respondents $(35.5 \%)$ are male. Regarding age, 31 respondents $(8.2 \%)$ were between 13 and 14 years old, 264 respondents (69.5\%) were 14-15 years old and 85 respondents (22.4\%) were between $15-16 \%$. Among all respondents, 157 respondents $(41.3 \%)$ indicated that they were in level 10, 122 respondents (32.1\%) were in level 11 and 101 respondents $(26.6 \%)$ were in level 12. Respondents were also asked about their grade in English, it was also then checked with the teachers' document and the results were the majority of them had a grade 
between 80-89 (175 respondents/46.1\%), the second grades were between 90-100 with 109 respondents $(28.7 \%)$, the next grades were between $70-79$ with 80 respondents $(21.1 \%)$ and only 16 respondents $(4.2 \%)$ had a score between $60-69$.

\subsection{High School Students' Language Learning Strategies}

The students' language learning strategies in English consist of fifty items divided into two main classes and six categories. The result of students language learning strategies can be seen at table 2. Although the level of use by strategies category differs in one way or another, all means for the six strategies categories fell within the range of 2.5-3.4, which indicates that the respondents used each strategies category at medium frequency.

Table 2. language learning strategies in English categories.

\begin{tabular}{|l|c|l|}
\hline Strategies & Mean & \multicolumn{1}{c|}{ Category } \\
\hline Memory (Remembering more effectively.) & 3.24 & Medium (sometimes used) \\
\hline Cognitive (Using all your mental processes) & 3.12 & Medium (sometimes used) \\
\hline $\begin{array}{l}\text { Compensation (Compensating for missing } \\
\text { knowledge.) }\end{array}$ & 3.11 & Medium (sometimes used) \\
\hline $\begin{array}{l}\text { Metacognitive (Organizing and evaluating } \\
\text { your learning) }\end{array}$ & 3.5 & High ( Usually used) \\
\hline $\begin{array}{l}\text { Affective (Managing your emotions) } \\
\text { Social (Learning with others) }\end{array}$ & 3.3 & Medium (sometimes used) \\
\hline
\end{tabular}

When looking at the data results in the Table 3 and with respect to the chart dealing with how often the pupils employ the individual strategies, it can be stated that only metacognitive strategies were usually used by students. The others five groups of strategies are sometimes employed by the students.

\subsection{Gender and Students' Language Learning Strategies in English}

Table 3 shows the Pearson product moment correlation result between gender and students' language learning strategies in English. As can be seen $\mathrm{r}$ result is 0.107 and $\mathrm{r}$ table value at df (379) and sig. level (0.05) is 0.037 , thus $r$ result is higher than $r$ table $(0.107>0.037)$ and it is indicated that there is a relationship between gender and language learning strategies in English.

This finding means that the strategies used by the students are influenced by their gender. In other words gender affected to the strategies use in which some researches also revealed that female subjects engaged in strategies use more frequently than male subjects

Table 3. Correlation results for gender and language learning strategies in English

\begin{tabular}{|l|l|r|r|}
\hline \multirow{3}{*}{ Gender } & & Gender & Learning Strategies \\
\hline \multirow{3}{*}{ Learning Strategies } & Pearson Correlation & 1 & $.107^{*}$ \\
\cline { 2 - 4 } & Sig. (2-tailed) & & .037 \\
\cline { 2 - 4 } & $\mathrm{N}$ & 380 & 380 \\
\cline { 2 - 4 } & Pearson Correlation & $.107^{*}$ & 1 \\
\cline { 2 - 4 } & Sig. (2-tailed) & .037 & 380 \\
\cline { 2 - 4 } & $\mathrm{N}$ & 380 & 38 \\
\hline
\end{tabular}




\subsection{Age and Students' Language Learning Strategies in English}

Table 4 shows the Pearson product moment correlation result between age and students' language learning strategies in English. As can be seen $r$ result is - 0.02 and $r$ table value at df (379) and sig. level $(0.05)$ is 0.973 , thus $r$ result is lower than $r$ table $(-0.02<0.972)$ and it is indicated that there is no relationship between age and language learning strategies in English.

This finding means that a different age of students will have no different in their learning strategies or age does not affect the students' learning strategies because older students employ the same strategies with the younger one.

Table 4. correlation results for age and language learning strategies in English

\begin{tabular}{|l|l|r|r|}
\hline \multirow{3}{*}{ Learning Strategies } & Learning Strategies & \multicolumn{1}{|c|}{ Age } \\
\cline { 2 - 4 } & Pearson Correlation & 1 & -.002 \\
\cline { 2 - 4 } & Sig. (2-tailed) & 380 & .973 \\
\cline { 2 - 4 } Age & $\mathrm{N}$ & -.002 & 380 \\
\cline { 2 - 4 } & Pearson Correlation & .973 & 1 \\
\cline { 2 - 4 } & Sig. (2-tailed) & 380 & 380 \\
\cline { 2 - 5 } & $\mathrm{N}$ & & \\
\hline
\end{tabular}

\subsection{Level and Students' Language Learning Strategies in English}

Table 5 shows the Pearson product moment correlation result between level and students' language learning strategies in English. As can be seen $r$ result is 0.055 and $r$ table value at $\mathrm{df}$ (379) and sig. level $(0.05)$ is 0.287 , thus $r$ result is lower than $r$ table $(0.055<0.287)$ and it is indicated that there is a no relationship between level and language learning strategies in English, meaning to say that level of education do not affected to the use of language learning strategies.

Table 5. Correlation results for age and language learning strategies in English

\begin{tabular}{|l|l|r|r|}
\hline & & Learning Strategies & \multicolumn{1}{|c|}{ Level } \\
\hline \multirow{3}{*}{ Learning Strategies } & Pearson Correlation & 1 & .055 \\
\cline { 2 - 4 } & Sig. (2-tailed) & 380 & .287 \\
\cline { 2 - 4 } & $\mathrm{N}$ & .055 & 380 \\
\hline \multirow{2}{*}{ Level } & Pearson Correlation & .287 & 1 \\
\cline { 2 - 4 } & Sig. (2-tailed) & 380 & 380 \\
\cline { 2 - 4 } & $\mathrm{N}$ & & \\
\hline
\end{tabular}

\subsection{Grade and Students' Language Learning Strategies in English}

Table 6 shows the Pearson product moment correlation result between grade in English and students' language learning strategies in English. As can be seen $r$ result is 0.162 and $r$ table value at $\mathrm{df}(379)$ and sig. level $(0.05)$ is 0.02 thus $r$ result is higher than $r$ table $(0.162<0.02)$ and it is indicated that there is a relationship between grade in English and language learning strategies in English. 
This finding means that the learning strategies used by students are influenced by their grade. On the other words, different achievement in English affected the language learning strategies use. Usually, clever students use better strategies in learning English than the lower one.

Table 6. Correlation results for grade in English and language learning strategies in English

\begin{tabular}{|l|l|r|r|}
\hline & & Learning Strategies & \multicolumn{1}{c|}{$\begin{array}{c}\text { Grade in } \\
\text { English }\end{array}$} \\
\hline Learning Strategies & Pearson Correlation & 1 & $.162^{* *}$ \\
\cline { 2 - 4 } & Sig. (2-tailed) & 380 & .002 \\
\cline { 2 - 4 } & $\mathrm{N}$ & $.162^{* *}$ & 380 \\
\hline \multirow{3}{*}{ Grade in English } & Pearson Correlation & .002 & 1 \\
\cline { 2 - 4 } & Sig. (2-tailed) & 380 & 380 \\
\cline { 2 - 4 } & $\mathrm{N}$ & & \\
\hline
\end{tabular}

\section{Conclusion}

On answering the question "Are there any significant relationships between the students' language learning strategy and their profile (gender, age, level and grade in English)?", the result indicates that there is a relationship between gender, grade in English and language learning strategy in English. However, there is a no relationship between age, level and language learning strategy in English.

\section{References}

[1] Z. Hu and I. McGrath, "Innovation in higher education in China: Are teachers ready to integrate ICT in English language teaching?," Technol. Pedagog. Educ., 2011, doi: 10.1080/1475939X.2011.554014.

[2] C. Kuo Lee, "an Overview of Language Learning Strategies," Arecls, 2010.

[3] K. Hong-Nam and A. G. Leavell, "Language learning strategy use of ESL students in an intensive English learning context," System, 2006, doi: 10.1016/j.system.2006.02.002.

[4] G. Wharton, "Language Learning Strategy Use of Bilingual Foreign Language Learners in Singapore," Lang. Learn., 2000, doi: 10.1111/0023-8333.00117.

[5] B. McCann, N. S. Keskar, C. Xiong, and R. Socher, "The natural language decathlon: Multitask learning as question answering," arXiv. 2018.

[6] L. L. C. Wong and D. Nunan, "The learning styles and strategies of effective language learners,” System, 2011, doi: 10.1016/j.system.2011.05.004.

[7] K. Wu, "The Relationship between Language Learners' Anxiety and Learning Strategy in the CLT Classrooms," Int. Educ. Stud., 2010, doi: 10.5539/ies.v3n1p174.

[8] N. D. Yang, "The relationship between EFL learners' beliefs and learning strategy use," System, 1999, doi: 10.1016/S0346-251X(99)00048-2.

[9] P. Liao, "EFL Learners' Beliefs about and Strategy Use of Translation in English Learning," RELC J., 2006, doi: 10.1177/0033688206067428.

[10] R. L. Oxford, "Strategy Inventory for Language Learning (SILL)," English, 1989.

[11] A. Chamot, "Issues in language learning strategy research and teaching," Electron. J. 
foreign Lang. Teach., 2004.

[12] R. L. Oxford et al., "The learning strategy prism: Perspectives of learning strategy experts," System, 2014, doi: 10.1016/j.system.2014.02.004. 